\title{
A Brief of China's OFDI in African Countries
}

\author{
Zhixin Xiong, Liyan Liu* \\ School of Economics and Management, Beijing Institute of Petrochemical Technology, Beijing, China \\ Email: *lucyliuliyan@bipt.edu.cn
}

How to cite this paper: Xiong, Z. X., \& Liu, L. Y. (2021). A Brief of China's OFDI in African Countries. Journal of Service Science and Management, 14, 469-481. https://doi.org/10.4236/jssm.2021.145030

Received: July 10, 2021

Accepted: October 8, 2021

Published: October 11, 2021

Copyright ( 2021 by author(s) and Scientific Research Publishing Inc. This work is licensed under the Creative Commons Attribution International License (CC BY 4.0).

http://creativecommons.org/licenses/by/4.0/ (c) (i) Open Access

\begin{abstract}
China has established good relations with African countries since the 1950s. In recent years, the investment enthusiasm in Africa has increased steadily in China. The research investigated the investment practice of China in African countries since the reform and opening, presented a general picture of Chinese FDI in African, and identified the status quo of Chinese investment from the perspective of investment volume, country distribution, industry distribution, and market maturity. Issues in policy support system, legal protection system, investment environment investigation, and operation mode are identified and analyzed, based on which corresponding countermeasures are proposed.
\end{abstract}

\section{Keywords}

China’s OFDI, African Countries, Status Quo, Counter Measures

\section{Introduction}

With the deepening of globalization and the increasingly fierce competition in the international market, participating in international investment has become one of the important ways to promote the development of the world economy. China has become a major OFDI (Outward Foreign Direct Investment) country in the world, with its foreign investment flow ranking second in the world and its foreign investment stock ranking third in the world. In the year 2019, China's outbound investment flow was approximately US $\$ 137$ billion. As for the stock, it reached 2.2 trillion US dollars, ranking third in the world. Investment destination countries involve 188 countries and regions, and investment along the "Belt and Road" economies has maintained a steady growth. In terms of proportion, a total of more than $80 \%$ of countries and regions have received Chinese investment, and the total assets of overseas enterprises have increased to 7.2 trillion US dollars. ${ }^{1}$

${ }^{*}$ Corresponding author: Liyan Liu.

${ }^{1}$ Report on Development of China's Outward Investment. Ministry of Commerce of the People's Republic of China, 2020. 
China's bilateral trade in China has grown rapidly in the past decades, and China has become the largest partner of African countries. As an emerging market, Africa has attracted capital investment from many countries. China has also increased its investment in Africa and expanded its investment scope. However, China's OFDI must face many problems concerned with some of the unmatured markets of Africa, such as the complex political and market environment in African countries. Therefore, how to find a development strategy that is more suitable for China's OFDI in Africa based on the actual conditions of the two sides is a key element in promoting a win-win situation in China-Africa cooperation. Through the analysis of status quo of China's direct investment, the current development level of China's investment in Africa can be reflected, and current issues be identified, to provide innovative suggestions for Chinese investment in African countries.

The current academic research mainly focuses on aspects as investment motivation analysis, risk analysis, and location selection. The research methods are mostly based on empirical analysis. Since the target countries of the research are relatively wide and the sample selection is diversified, the conclusions drawn are naturally different. This study focused on China's investment in African countries since reform and opening, draw a clear picture of the investment from development to current characteristics, identified the general issues and proposed corresponding solutions applicable for most Chinese investments in African countries, providing general support and guidance for Chinese enterprises endeavor to invest in Africa. However, the study does not investigate investments in each specific country in Africa, and the solutions are more general but not specific; for example, how to invest in a particular country in Africa for a particular industry is not discussed in the study, which is the limitation of the study.

\section{Literature Review}

With the development of China's economy and the strengthening of the globalization trend in the international market, scholars have carried out wide studies in China's foreign investment strategy and structure. In the field of investment in African countries, the study is largely based on investment motivations, influencing factors, risks, and impact categories.

Natural resources have always affected the value choices of most investment countries. One of the purposes of OFDI is to obtain resources from the target country to gain economic growth. Compared with countries with limited non-productive resources, China has a strong willingness to invest in countries with abundant resources. Song Weijia and Xu Hongwei (2012) pointed out that the distribution of Chinese investment in African countries shows that Chinese investment is highly concentrated in several countries with natural resources, such as oil and minerals. Therefore, it can be concluded that the main driving force for China's investment in these countries is their resource endowment rather than the size of the local market. Gao Yu (2012) believed that investment 
has changed from resource-seeking motivation to market-seeking motivation. African countries with market advantages and resources advantages will attract more Chinese direct investment. Liu Xinjie (2018) analyzed the mechanism of expansion of China's foreign investment, and found that the fundamental purpose of China's foreign investment is to further open the international market and obtain the resources needed for development. Jiang Guanhong and Jiang Dianchun (2012) also investigated the location selection of OFDI in China through the gravity model. They also came to similar conclusions, that the motivation of China's OFDI is more of seeking markets, resources and strategic assets, and the host country system also has a significant impact on OFDI.

In terms of the economic impact of China's foreign investment on Africa, Wang Xian et al. (2020) used the Theil index and panel data fixed-effects model to study the temporal and spatial changes and influencing factors of foreign direct investment in Africa. The investment has an active role in promoting East Africa and South Africa economic development, but it has a negative effect on West African countries; African countries' industrial structure have little impact on China's investment, but the political environment and resource endowment present strong relations with the total amount of direct investment. Except for South Africa, infrastructure has little effect on the inflow of FDI from mainland China. In addition, Liu Yang (2020) also applied panel data analysis and concluded that China's OFDI does have a positive impact on the development of African economies.

With regard to the risks of Chinese firms investing in Africa, Han Jie and Wang Xuan (2020) focused on location analysis to predict the possible risks of OFDI. Based on the 2006-2017 data of 16 countries including Sudan and South Africa that have signed cooperation agreements with China to jointly build the "Belt and Road", through political factors, development level factors analysis, and comprehensive analysis of economic growth factors, they discussed the impact of political and economic risks on Chinese firms' outward investment. Combined with local location factors, resource motives and market motives, Zhou Pinghua and Yao Tianyu (2020) analyzed the possible political, economic, legal, medical, health, and climate risks of OFDI.

Concerning research on host country government governance and political environment, Wang Jian and Zhang Hong (2011) conducted an empirical analysis of government governance and direct investment, and found that China's investment targets are generally in countries with high government efficiency, and basically do not involve countries and regions with high levels of corruption. Chen Song and Liu Haiyun (2012) found that China's foreign investment in the past is full of humanistic care. Most African countries that accept Chinese investment have weak economic foundations and relatively low government efficiency. The governance level of the host country is negatively correlated with investment level. Chen Chusheng et al. (2017) conducted research on the institutional environment of target countries and pointed out that countries with 
superior institutional environments and strong economic strength are more likely to be favored by Chinese investment. However, some scholars have come to different conclusions. Among them, Wu Xianming and $\mathrm{Hu}$ Cuiping (2015) pointed out that there is a negative correlation with the legal environment and China's direct investment in Africa, but the political system does not seem to have too much influence. This contradictory conclusion may be due to the different choices of variables.

In addition, there are studies focused on the determinants of China's OFDI decision-making (Luo \& Ge, 2013), the factors affecting OFDI output (Yao \& Sun, 2007), the geographic distance of investment (Gao, 2009), and OFDI management issues (Liu \& Wang, 2017).

To sum up, scholars have attached great importance to Sino-African trade exchanges, and have produced many research results in different directions, and the research methods used are also relatively diverse. The focus of research has gradually shifted to investment motivation analysis, risk analysis, and location selection. Research methods are mostly based on empirical analysis. The scope of target countries is relatively wide, and the sample selections are diversified, hence, the conclusions drawn are correspondingly different, and may not be sufficient to serve as a guide for Chinese enterprises to invest in African countries. This study focused on the specific aspect as Chinese investments in African countries, identified general issues and applicable suggestions serving as a support and general guidance for Chinese investments in Africa.

\section{The Status Quo of China's Direct Investment in Africa}

Based on the information and data from Report on Development of China's Outward Investment, and China's outward investment statistics from National Bureau of Statistics, we summarized the status quo of China's direct investment in Africa.

\subsection{The Development Stage of China's Direct Investment in Africa}

\section{First phase: 1978 to 1990 s}

After the reform and opening in 1978, Chinese firms began to set off a wave of investment. Under the influence of this investment trend, the investment methods and scale of African countries have undergone major changes. Large and small enterprises have launched a series of investment cooperation programs based on traditional forms, such as economic assistance. However, the behavior of investing in Africa at that time was still immature, and investors did not particularly understand the local situation. In addition, there were unclear knowledge of international law and other risk-identification problems. Therefore, during that period, the amount of China's direct investment in African countries is quite small, the scope and size of investment are narrow, and most of them are concentrated in specific industries, mostly confined in several industry sectors and agriculture, followed by restaurant and resource development. 


\section{Second phase: 1990 s to 2005}

During this period, with the deepening of opening to the outside and the development of globalization, Africa has increasingly become one of the important partners of economic and trade cooperation. After the end of the China-Africa Ministerial Cooperation Forum in 2000, China-Africa trade exchanges were pushed to the peak. The forum is a sign that China and Africa have officially entered a new era in history. Economic exchanges between China and African countries have become more frequent, and trade partnerships have become increasingly close. In 2000 alone, China's total investment in Africa exceeded 200 million yuan.

\section{Third phase: 2006 to present}

In 2006, the Chinese government tried to continuously expand its investment in Africa, and actively signed many bilateral agreements to negotiate measures to avoid double taxation with many countries. At the same time, a series of policy support such as preferential credit has been issued to support and encourage firms to invest in Africa. In 2007, the China-Africa Development Fund was established, which gave China-Africa investment activities a greater impetus. Since then, more cooperation has been made in aspects of economy, society and humanities. At the end of 2019, the total flow of investment in Africa has increased by 13 times, reaching 2.7 billion.

\subsection{General Profile of China's Direct Investment in Africa}

From the perspective of investment flow, China's direct investment in Africa has increased significantly since 2006, which has shown a fluctuating growth. The peak was in the year 2008, which reached an increase of $249 \%$. the second was in the year 2018, which was 31.5\%. Although the flow of OFDI has fluctuated greatly, the overall FDI flow has increased from US\$520 million in 2006 to US\$2.71 billion in 2019, indicating that overall China's FDI to Africa is growing amidst fluctuations. ${ }^{2}$

In terms of investment stock, according to statistics released by the Ministry of Commerce, China's foreign investment stock reached US\$2.2 trillion as of 2019 , making it the third largest country in the world, an increase of US\$216.61 billion from the end of the previous year. By the end of year 2019, China's total direct investment stock in African countries has reached 44.39 billion U.S. dollars, which is 17 times of year 2006. In terms of the stock growth rate, despite the declining trend since year 2008, the overall average annual growth rate from 2006 to 2019 still reached $26.51 \%$. However, it should be noted that the stock of foreign direct investment in Africa only accounts for $2 \%$ of China's total foreign direct investment stock. Compared with other regions, China's direct investment in Africa remains quite low. ${ }^{3}$

\footnotetext{
${ }^{2}$ Report on Development of China's Outward Investment. Ministry of Commerce of the People's Republic of China, 2016-2020.

${ }^{3}$ Report on Development of China's Outward Investment. Ministry of Commerce of the People's Republic of China, 2016-2020.
} 
From the perspective of destination countries, the top three countries are South Africa, Congo (DRC) and Angola, which presents a quite different result from China's current investment tendency. Even in South Africa, which received most of China's direct investment, China's proportion only accounted for $4 \%$ of the country's total in the year 2019, showing that although the overall scale of China's FDI in African countries has been steadily increasing, compared with other developed countries in the world, the size of China's direct investment is still quite small.

From the perspective of the composition of the investment industry, by the end of 2019, China's direct investment has covered almost all sectors of industries. Among them, construction, mining, manufacturing, and financial industries account for a large proportion, accounting for almost $85 \%$ of the total investment. The total investment stock has reached 37.94 billion U.S. dollars, of which the construction industry accounts for the largest proportion of $30.6 \%$, indicating China's investment is still focused on local infrastructure construction, which may be a continuation of experience in aid to Africa in the past decades. In recent years, with the continuous development of infrastructure construction, Chinese firms have gradually increased their investment in financial and service industries in Africa.

\subsection{Characteristics of China's Direct Investment in Africa}

\subsubsection{The Total Investment Volume Is Still Quite Low}

China's investment in Africa has made the fastest progress with a steady growth rate since the year 2000. However, Africa is still one of the least in China's foreign investment destination areas, compared with other Asian, European, and American areas, and the investment stock is still small. In the year 2019, Asia accounts for 66.45 of China's direct investment 66.4\%, Latin America accounts for $19.8 \%$, Europe accounts for 5.2\%, North America accounts for $4.6 \%$, and Africa and Oceania both account for $2.0 \%{ }^{4}$ The results may be due to the political stability. According to the 2015 report by the World Economic Forum, African countries are inferior to developing countries other than South Asia in terms of corruption index. Corruption will reduce firms' efficiency, which is not conducive to cultivating firms' enthusiasm for operation, but also forcing firms to increase operating costs, hence negatively impact investment.

\subsubsection{The Country Distribution Is Relatively Concentrated}

As China's "going out" strategy is deepened, investment in Africa has continued to increase, while the investment scope and industry coverage have also continued to expand, formed a relatively stable status. As of the year 2019, China's direct investment has gradually covered 52 countries and regions in Africa, however, the investment in specific countries is still unbalanced. Investments still concentrated in a few African countries. From the perspective of investment ${ }^{4}$ Report on Development of China's Outward Investment. Ministry of Commerce of the People's Republic of China, 2016-2020. 
stock, the top ten countries in the investment stock account for $65.9 \%$ of the total, indicating that the specific distribution of China's investment in Africa is relatively concentrated.

\subsubsection{The Investment Industry Is Unevenly Distributed}

According to the above analysis, investment in the five sectors of construction, finance, manufacturing, minerals, and services accounts for about $85 \%$ of the total investment in Arica, and the construction industry alone accounts for more than $30 \%$. In fact, this is related to the specific conditions of most African countries, since some countries face the need for infrastructure construction, and China has advantage in infrastructure construction in terms of both technology and speed, many African countries have chosen to cooperate with China. This also shows that the industry distribution of China's investment is still uneven, and the concentration is obvious.

\subsubsection{The African Market Is Still Immature}

The market development of some African countries is still immature, and there are economic and legal risks that are not conducive to the growth of foreign investment. In recent years, the international financial market has been ups and downs, and the form of economic development has been relatively obscure. In some African countries, the financial market is not well-established, and the ability to resist risks is generally weak, which is subject to the level of domestic economic development and is vulnerable to fluctuations in the international financial market. In addition, due to the lack of government experience in macroeconomic regulation and control, some African countries have over-issued currencies, leading to inflation. Besides, some countries' mode of economic growth is relatively simple and lack effective domestic demand stimulus, which creates economic risks and is not conducive to attracting foreign investment. In addition, in terms of legal systems, due to the frequent changes of regimes in some African countries, the contract terms that have been signed under some government management may not be able to continue to take effect.

\section{Issues of China's Direct Investment in Africa}

With the rapid influx of Chinese investment into Africa, problems have emerged both in macro and micro aspects. Macro risks include political conditions, government services and management, foreign exchange, etc. Micro-level risks include business operations, labor management, technical difficulties, etc. As China still accounts for a minority in Africa and Chinese investment has insufficient experience, there are still limitations in Chinese direct investments.

\subsection{Insufficient Policy Support System}

At present, China has direct investment in 52 African countries or regions, and each country has its own national conditions and presents different market environments and development prospects. However, there is still a huge gap in 
China's research on the macro-environment of African countries, and the risk warning mechanism for investment in Africa has not been fully established yet.

On the macro level, China's laws on overseas investment started relatively late, so the legal system related to overseas investment is still in need to improve. At the same time, data shows that the number of countries that received investment is greater than the number of countries that have signed bilateral agreements with China, indicating that some Chinese investors are still outside the scope of protection of bilateral agreements.

In addition to bilateral agreements, investors can usually rely on multilateral mechanisms to protect their corporate interests, especially in areas such as Afri$\mathrm{ca}$, where investment countries are diverse and some of the legal systems are not sound enough. China is already the signatory to the Treaty of the Multilateral Investment Guarantee Agency (MIGA), most Chinese firms lack sufficient knowledge of MIGA, and some small and medium-sized firms even have no knowledge of the treaty.

\subsection{Incomplete Legal Protection System}

Compared with many Western countries, China has a shorter investment period in Africa. The projects invested by Western countries in Africa are mainly concentrated in industries with relatively high profit margins, such as the service industry and the financial industry. However, China's investment projects are mainly in industries with relatively low profits such as construction, mining, and manufacturing, and the policies of these industries are volatile.

Moreover, China's investment in Africa is a complex process. The process not only tests the firm itself, but also involves the cooperation of multiple government departments. However, at present, various government departments have different target plans, lack of a sufficiently unified overall layout. An imperfect coordination mechanism makes collaboration difficult and hinders the implementation of the project. It is precisely because of the imperfect inter-departmental coordination mechanism that makes many domestic preferential policies difficult to be implemented, hence, increase firms' investment cost and decrease firms' comparative advantage.

\subsection{Insufficient Understanding of the Investment Environment}

China and Africa are far away in terms of space, and many Chinese firms have a relatively superficial understanding of African countries. In addition, the political, social, and legal environment of some African countries is unfamiliar for Chinese firms. The understanding process is inherently difficult, and it is not easy to make investment decisions. Misunderstanding of the investment environment may occur, especially when it is refined to a certain country or a certain industry. At the same time, there are quite few research institutions focusing on investments in specific African countries. For most investors, basically only the "Guidelines for Foreign Investment Cooperation Countries (Regions)" issued by 
the Ministry of Commerce can be used as a guide for understanding of the target African country. As a result, China's investment in many African countries must be constrained to cross the river by feeling the stones.

The proportion of small and medium-sized firms investing in Africa is experiencing a trend of rapid growth. However, these firms' economic strength is limited, its ability to resist risks is insufficient, and its competitiveness in the market is not strong. The policies, social structures, and political systems of different countries in Africa are complicated, and most firms investing in Africa lack research on the investment environment in Africa, the understanding and analysis of their own conditions, and the clear strategic plan for the African market.

This impact is mainly reflected in two aspects. On the one hand, it is easy for companies to make incorrect assessments of the market, resulting in a relatively blind production and sales situation, and cannot accurately respond to the actual market supply and demand and consumption capacity, resulting in well-known decision-making errors. At the same time, we will also find that these operational errors due to insufficient preparations may not only exist in firms' actions, but may also exist in the individual actions of the firm's employees, leading to major top-down corporate errors. On the other hand, China's Investment in Africa has a relatively strong nature of assistance in any period. This nature does not mean that investment does not have risks, firms still face political and financial risks. The risk has not been substantially changed.

\subsection{Imperfect Operation Mode}

Although most of the small and medium-sized enterprises are developing rapidly, they have no comprehensive and mature investment experience to learn from, so the understanding of the African economic system and the formulation of investment strategies are not yet mature. Coupled with its weak economic strength, small economic scale, weak product competitiveness and poor anti-risk capabilities, it often runs into obstacles in the African market, which is also not conducive to the development of foreign direct investment activities.

Private firms have mixed good and bad, and some firms, especially some trading firms, have short-term operations. Because large private firms are usually well prepared and aim to operate in Africa for a long time, they are relatively daring to take risks. However, small and medium-sized firms often lack funds due to insufficient strength, so their investment is often short-term. In addition, due to human resources limitations and language barriers, these firms will be more inclined to make money to recover the initial investment costs, rather than expand the scale to do long-term business. Coupled with the deteriorating business environment of the trade industry, as well as the depreciation of the local currency and government corruption, firms may have insufficient confidence in the future of development in Africa and have a passing mentality, hence ignore the importance of building a corporate image, perfecting corporate culture, and 
lack the sense of social responsibility, which will cause dissatisfaction and even hostility from local residents or firms, which make it difficult for investment firms to integrate into the local society.

\section{Suggestions for Optimizing China's Direct Investment in Africa}

Combining the status quo of Chinese firms' direct investment in Africa and the various problems they are currently facing, the author intends to start from the macro perspective and the corporate perspective, propose the following suggestions.

\subsection{Build a Good External Environmental System}

Many international cooperation relations have proved that political mutual trust has always been the basis for establishing good trade relations. At the same time, this friendly atmosphere has been passed on to all levels of the economy, culture and society, providing a broad stage for investment expansion. In addition, bilateral trade agreements are currently the major means of dealing with international trade. This type of agreement stipulates the specific responsibilities, obligations, and rights of the two countries, and guarantees the security of trade between the two parties.

At present, some Chinese firms are kind of order-lacking in their overseas investments. Therefore, both legal support and legal constraints are needed when making indirect investments. It is possible to establish a special overseas investment insurance system and other related legal constructions, and at the same time accelerate the signing of agreements with more African countries such as promoting bilateral trade and avoiding double taxation agreements and supervise the implementation of policies to ensure the implementation of relevant laws and policies.

The government can also provide high-quality firms with foreign investment loan services, broaden the financing channels, and improve financing situations of small and medium-sized firms, and help more high-quality firms go abroad to achieve development and growth. At the same time, the government can guide firms with real market information to gain a correct understanding of investment risks, political risks, and war risks.

\subsection{Improve the Pre-Investment Market Research and Environment Analysis}

In the process of direct investment in Africa, Chinese firms should combine their strategic goals with the advantages and disadvantages of their firms' industry, to choose an investment destination purposefully.

The most important thing is to build a good investment platform to publicize detailed information about African countries so that firms can make reasonable decisions. This is an effective way for firms to understand the political system 
and legal environment of African countries. It may be necessary to establish a special investigation team to fully understand the actual situation of the local area, to timely grasp the various risk factors and investment costs that exist in investment, to avoid the emergence of follow-up and blind investment methods, and to provide a true reference for enterprise development decisions.

\subsection{Establish an Internal Risk Management System}

When firms are operating overseas, they should create an internal early warning mechanism to predict and resolve risks arising from foreign investment. Only when a complete risk warning and management system is established, can firms effectively predict before the arrival of risks, and take active and timely response strategies when risks occur. A scientific and effective risk identification, prevention and control mechanism is especially important for investment, and it also determines whether firms can obtain economic benefits and succeed in investing in Africa.

In addition to preparing for the realization of investment, and analyzing the market environment, institutional environment and legal environment of the target country, firms should also choose to use localization strategies and be guided by the target country's market to provide with products of this quality. A good foundation of trust should be established in the contacts, paving the way for expanding investment, gaining trust at the political, economic, and cultural level, and effectively avoiding the influence of political risks. In addition, a company's comprehensive risk management system should also include the aftermath of political risks. Some companies have no intention to evade responsibility, but lack effective coordination and communication methods, which resulting in problems that cannot be properly handled. At this time, firms can request the help of local law or international arbitration to coordinate the conflicts.

\subsection{Strengthen Ties with Local Society and Media}

Regarding the social risks in direct investment, firms may start from two perspectives: communicating with local overseas Chinese and promoting corporate image with local media.

Overseas Chinese or Chinese living in Africa are unique advantages for companies that have just entered the African market, and they can play an important role in establishing close ties between Chines firms and Africa. This is because compared with the newcomer, the local overseas Chinese may have a full understanding of the local humanities, customs, legal characteristics, etc., and can help Chinese companies in many aspects.

As for the issues of inefficient communication between Chinese firms and the local people, and the poor corporate image, firms should actively negotiate and communicate with relevant local authorities and take efforts on image building. At the same time, wind reviews can also strengthen contacts with local media and convey serious and responsible development concepts, such as holding reg- 
ular open-visit business operations activities, etc., through these activities to build a social atmosphere conducive to corporate development.

\section{Conclusion}

The current situation of China's direct investment in Africa presents the following three characteristics: First, the total investment is developing steadily, but the total volume is still low, accounting for only $2 \%$ of China's total foreign investment. Second, the country distribution is relatively concentrated. The top ten countries among 52 countries and regions in Africa account for $65.9 \%$ of the total investment stock. The third is the concentration of investment industries, of which the construction industry (construction industry) alone accounts for $30.6 \%$.

Chinese investors are emerging investors in African markets, facing various aspects of problems. To deal with the problems identified, the author made suggestions for dealing with the above problems from the macro- and micro-perspectives. Chinese firms should first improve the pre-investment market research together with investment environment analysis and strive to establish a sound internal risk management system. At the same time, they should strengthen their contacts with local society and the media. The Chinese government needs to further improve the legal construction related to foreign direct investment, and at the same time strengthen the state's support for foreign direct investment and friendly bilateral relations with African countries to provide multi-faceted support and guarantee for firms' direct investment.

\section{Supporting Projects}

OFDI's performance from the perspective of firm heterogeneity, Beijing URT Project (2020J00064).

\section{Conflicts of Interest}

The authors declare no conflicts of interest regarding the publication of this paper.

\section{References}

Chen, C. S., Liu, X. D., \& Yi, C. J. (2017). The Influence of Overseas Chinese Business Network and Host Country's Institutional Environment on China's OFDI-Based on the Research Perspective of "One Belt One Road". Journal of Fujian Normal University (Philosophy and Social Sciences Edition), No. 1, 79-86+169.

Chen, S., \& Liu, H. Y. (2012). The Impact of Host Country Governance on the Location of China's Foreign Direct Investment-An Empirical Study Based on Panel Data Model. Research on Economy and Management, No. 6, 71-78.

Gao, G. W. (2009). International Direct Investment and Gravity Model. World Economy Studies, No. 11, 82-86+89.

Gao, Y. (2012). Chinese Companies Investing in Africa: Market and Resource Orientation-Tobit Analysis Based on Panel Data. International Economics and Trade Re- 
search, 28, 82-93.

Han, J., \& Wang, X. (2020). Research on the Risks of Chinese Enterprises' Direct Investment in Africa under the Background of the "Belt and Road". China Business Theory, No. 12, 94-98.

Jiang, G. H., \& Jiang, D. C. (2012). Location Selection of China's Foreign Investment: Panel Data Test Based on Investment Gravity Model. The World Economy, 35, 21-40.

Liu, A., \& Wang, Z. X. (2017). The "Third-Party Effect” of China's Direct Investment in Africa under the Background of "One Belt One Road"-An Empirical Test Based on Spatial Panel Data. International Business, No. 4, 100-112.

Liu, X. J. (2018). The Motivation and Location Selection of Chinese Enterprises' Foreign Direct Investment (pp. 31-42). South China University of Technology.

Liu, Y. (2020). The Impact of China's OFDI on African Economic Growth-Based on Panel Data Analysis of 38 African Countries. Productivity Research, No. 2, 17-19+32.

Luo, W., \& Ge, S. Q. (2013). The Location Distribution of China's Foreign Direct Investment and Its Determinants: A Study Based on Horizontal Investment. Economics (Quarterly), 12, 1443-1464.

Song, W. J., \& Xu, H. W. (2012). Research on the Influencing Factors of Location Choice of Foreign Direct Investment. Research on Financial and Economic Issues, No. 10, 44-50.

Wang, J., \& Zhang, H. (2011). Research on the Relationship between Host Country Government Governance and China's Foreign Direct Investment-An Empirical Analysis Based on Host Country Panel Data. Asia Pacific Economics, No. 1, 127-132.

Wang, X., Liu, B. L., \& Zhang, Z. K. (2020). Temporal and Spatial Changes and Influencing Factors of Foreign Direct Investment in Africa. World Geographical Research, 29, 1125-1135.

Wu, X. M., \& Hu, C. P. (2015). Internationalization Motives, Institutional Environment and Location Selection: The Perspective of Latecomer Enterprises. Economy and Management, 37, 51-62.

Yao, L. M., \& Sun, C. Y. (2007). An Empirical Analysis of the Determinants of China's Reverse FDI. Journal of International Trade, No. 4, 81-86.

Zhou, P. H., \& Yao, T. Y. (2020). Analysis of Chinese Enterprises' Overseas Investment Motivations and Risks-Based on the Perspective of Different Types of Host Countries. Shanxi Finance and Taxation, No. 7, 40-44. 